\title{
High diversity and suggested endemicity of culturable Actinobacteria in an extremely oligotrophic desert oasis
}

\author{
Hector Fernando Arocha-Garza ${ }^{1}$ ， Ricardo Canales-Del Castillo ${ }^{2}$, Luis E. Eguiarte ${ }^{3}$, Valeria Souza ${ }^{3}$, Susana \\ De la Torre-Zavala ${ }^{\text {Corresp. } 1}$ \\ 1 Facultad de Ciencias Biológicas, Instituto de Biotecnología, Universidad Autónoma de Nuevo León, San Nicolás de los Garza, Nuevo Leon, México
2 Facultad de Ciencias Biológicas, Laboratorio de Biología de la Conservación, Universidad Autónoma de Nuevo León, San Nicolás de los Garza, Nuevo
León, Mexico \\ 3 Departamento de Ecología Evolutiva, Instituto de Ecología, Universidad Nacional Autónoma de México, Mexico City, Mexico \\ Corresponding Author: Susana De la Torre-Zavala \\ Email address: susana.delatorrezv@uanl.edu.mx
}

The phylum Actinobacteria constitutes one of the largest and anciently divergent phyla within the Bacteria domain. Actinobacterial diversity has been thoroughly researched in various environments due to its unique biotechnological potential. Such studies have focused mostly on soil communities, but more recently marine and extreme environments have also been explored, finding rare taxa and demonstrating dispersal limitation and biogeographic patterns for Streptomyces. To test the distribution of Actinobacteria populations on a small scale, we chose the extremely oligotrophic and biodiverse Cuatro Cienegas Basin (CCB), an endangered oasis in the Chihuahuan desert to assess the diversity and uniqueness of Actinobacteria in the Churince System with a culturedependent approach over a period of three years, using nine selective media. The $16 \mathrm{~S}$ rDNA of putative Actinobacteria were sequenced using both bacteria universal and phylum-specific primer pairs. Phylogenetic reconstructions were performed to analyze OTUs clustering and taxonomic identification of the isolates in an evolutionary context, using validated type species of Streptomyces from previously phylogenies as a reference. Rarefaction analysis for total Actinobacteria and for Streptomyces isolates were performed to estimate species' richness in the intermediate lagoon (IL) in the oligotrophic Churince system. A total of 350 morphologically and nutritionally diverse isolates were successfully cultured and characterized as members of the Phylum Actinobacteria. 105 from the total isolates were successfully subcultured, processed for DNA extraction and 16S-rDNA sequenced. All strains belong to the order Actinomycetales, encompassing 11 genera of Actinobacteria; the genus Streptomyces was found to be the most abundant taxa in all the media tested throughout the 3-year sampling period. Phylogenetic analysis of our isolates and another 667 reference strains of the family Streptomycetaceae shows that our isolation effort produced 38 unique OTUs in six new monophyletic clades. This high 
biodiversity and uniqueness of Actinobacteria in an extreme oligotrophic environment, which has previously been reported for its diversity and endemicity, is a suggestive sign of microbial biogeography of Actinobacteria and it also represents an invaluable source of biological material for future ecological and bioprospecting studies. 
1 High diversity and suggested endemicity of culturable Actinobacteria in an extremely

2 oligotrophic desert oasis.

3

4 Héctor Fernando Arocha-Garza ${ }^{1}$, Ricardo Canales-delCastillo ${ }^{2}$, Luis E. Eguiarte ${ }^{3}$, Valeria

5 Souza $^{3}$, Susana De la Torre-Zavala ${ }^{1}$

6

7

8 Instituto de Biotecnología. Facultad de Ciencias Biológicas, Universidad Autónoma de Nuevo

9 León. San Nicolás de los Garza, N.L., México.

10 2Laboratorio de Biología de la Conservación. Facultad de Ciencias Biológicas, Universidad

11 Autónoma de Nuevo León. San Nicolás de los Garza, N.L., México.

$12{ }^{3}$ Departamento de Ecología Evolutiva. Instituto de Ecología. Universidad Nacional Autónoma de 13 México. Coyoacán, México, D.F. México.

Corresponding author:

${ }^{1}$ Susana De la Torre Zavala.

Ave. Pedro de Alba y Manuel L. Barragan. S/N. Ciudad Universitaria. San Nicolás de los Garza, N.L., 66455, México.

E-mail: 
24 Abstract. (332 words)

25 The phylum Actinobacteria constitutes one of the largest and anciently divergent phyla within the Bacteria domain. Actinobacterial diversity has been thoroughly researched in various environments due to its unique biotechnological potential. Such studies have focused mostly on soil communities, but more recently marine and extreme environments have also been explored, finding rare taxa and demonstrating dispersal limitation and biogeographic patterns for Streptomyces. To test the distribution of Actinobacteria populations on a small scale, we chose the extremely oligotrophic and biodiverse Cuatro Cienegas Basin (CCB), an endangered oasis in the Chihuahuan desert to assess the diversity and uniqueness of Actinobacteria in the Churince System with a culture-dependent approach over a period of three years, using nine selective media. The 16S rDNA of putative Actinobacteria were sequenced using both bacteria universal and phylum-specific primer pairs. Phylogenetic reconstructions were performed to analyze OTUs clustering and taxonomic identification of the isolates in an evolutionary context, using validated type species of Streptomyces from previously phylogenies as a reference. Rarefaction analysis for total Actinobacteria and for Streptomyces isolates were performed to estimate species' richness in the intermediate lagoon (IL) in the oligotrophic Churince system. A total of 350 morphologically and nutritionally diverse isolates were successfully cultured and characterized as members of the Phylum Actinobacteria. 105 from the total isolates were successfully subcultured, processed for DNA extraction and 16S-rDNA sequenced. All strains belong to the order Actinomycetales, encompassing 11 genera of Actinobacteria; the genus

44 Streptomyces was found to be the most abundant taxa in all the media tested throughout the 3year sampling period. Phylogenetic analysis of our isolates and another 667 reference strains of the family Streptomycetaceae shows that our isolation effort produced 38 unique OTUs in six 
47 new monophyletic clades. This high biodiversity and uniqueness of Actinobacteria in an extreme

48 oligotrophic environment, which has previously been reported for its diversity and endemicity, is

49 a suggestive sign of microbial biogeography of Actinobacteria and it also represents an

50 invaluable source of biological material for future ecological and bioprospecting studies.

51 
53

54

55

56

57

58

59

60

61

62

63

64

\section{Introduction}

The phylum Actinobacteria are gram-positive bacteria with a high $\mathrm{G}+\mathrm{C}$ content, and it constitutes one of the largest phyla within the Bacteria domain (Parte, Whitman, Goodfellow 2012). Actinobacteria diversity and community structure have been thoroughly researched in various environments. However, such studies had focused mostly in soil communities (Coombs \& Franco 2003; Gremion, Chatzinotas \& Harms 2003; Mohammadipanah \& Wink 2015; Zhao, Guo, Li 2016); but more recently, marine environments have also been explored (Ward \& Bora 2006; Maldonado, Fragoso-Yanez, Perez-Garcia 2009; Claverias, Undabarrena, Gonzalez 2015; Duran, Bielen, Paradzik 2015; Chen, Zhang, Guo 2016; Mahmoud \& Kalendar 2016;

Undabarrena, Beltrametti, Claverias 2016).

As an indicator of their ecological importance, Actinomycetes, filamentous members of the phylum Actinobacteria account for about 10\% of bacteria colonizing marine aggregates (Grossart, Schlingloff, Bernhard 2004). Initially, marine Actinomycetes were poorly characterized (Goodfellow \& Williams 1983), but more recently, culture independent studies have shown that marine Actinomycetes are diverse and abundant (Ward \& Bora 2006). Rare marine Actinomycetes taxa have been isolated from a range of depths, sediments and other microbial communities such as stromatolites (Allen, Goh, Burns 2009). Actinomycetes also comprise about $10 \%$ of the microbiome of extreme habitats, showing extensive taxonomic diversity (Kuhn, Ichimura, Peng 2014; Mohammadipanah \& Wink 2015; Liu, Salam, Jiao 2016; Qin, Li, Dastager 2016). However, careful population studies must still be done to determine if Actinomycetes are cosmopolitan, or if they do have local ecotypes, i.e., some degree of biogeography. Endemism would be the clearest demonstration of microbial biogeography, as it is for other organisms such as Salinisporaㄹ. Mafnas 2006; Winsborough, Theriot \& Czarnecki 2009; Coghill, Hulsey, Chaves-Campos 2013; Prieto- 
77 Davo, Villarreal-Gomez, Forschner-Dancause 2013). Nevertheless, to unambiguously accept the idea

78 of unlimited dispersal of microorganisms, we need data from studies employing good sampling.

79 Such is the case, for example, of Escherichia coli, human-related strains of which travel with

80 their host all around the world, or the case of Bacillus subtilis that can form endospores and

81 travel with the air ?(Souza, Eguiarte, Travisano 2012). Even in such cosmopolitan bacteria, there

82 are local ecotypes that are unrelated to any other known strains ?(Gonzalez-Gonzalez, Sanchez-

83 Reyes, Delgado Sapien 2013; Avitia, Escalante, Rebollar 2014; Valdivia-Anistro, Eguiarte-

84 Fruns, Delgado-Sapien 2015). Streptomyces, a filament and spore producer, and the most

85 extensively studied genera of Actinomycetes, has been studied and it had shown environmental

86 gradients and regional endemism in some localities ?(Davelos, Xiao, Samac 2004; Antony-Babu,

87 Stach \& Goodfellow 2008; Kinkel, Schlatter, Xiao 2014; Andam, Doroghazi, Campbell 2016).

Actinobacterial diversity and community structure have been thoroughly investigated, not

only for their ecological importance, but also by virtue of their unique biotechnological potential

due to their robust secondary metabolism and incomparable ability to produce a plethora of

bioactive molecules with extensive medical, industrial and agricultural applications.

Actinomycetes, are the source of most clinically relevant antibiotics in use today (Barka, Vatsa,

Sanchez 2016). Nevertheless, the growing emergence of antibiotic multirresistant pathogenic

strains, challenges the scientific community to overcome the problem of rediscovery of known

be facilitated by focusing heavily on "gifted" (secondary-metabolites-rich), readily culturable

microbes that have been isolated from untapped environments, such as marine ecosystems, which enhance the isolation of large-genome $(>8 \mathrm{Mb})$, thus, rare culturable bacteria (Tiwari \& 
100 Katz \& Baltz 2016; Smanski, Schlatter \& Kinkel 2016).

101 Correspondingly, efforts towards describing the extent of the diversity of culturable

102 actinomycetes on different conditions and extreme environments have been done, as evidenced

103 by recent reports of bioprospecting and diversity studies of actinobacteria on deserts, marine

104 sediments and vents, coral reefs, glaciers, as well as in symbiotic relationships (Maldonado et al.,

105 2009; Rateb, Houssen, Harrison 2011; Lee, Zainal, Azman 2014; Duncan, Haltli, Gill 2015;

106 Duran et al., 2015; Jami, Ghanbari, Kneifel 2015; Kuang, Li, Zhang 2015; Mohammadipanah \&

107 Wink 2015; Trujillo, Riesco, Benito 2015; Yang, Li, Huang 2015; Andam et al., 2016; Chen et

108 al., 2016; Liu et al., 2016; Mahmoud \& Kalendar 2016; Undabarrena et al., 2016).

To assess the extent of morphological and metabolic diversity and the distribution of

110 culturable actinobacteria populations on a local scale, we chose the extremely oligotrophic and

111 biodiverse Cuatro Cienegas Basin (CCB), an endangered oasis in the Chihuahuan desert (Souza,

112 Siefert, Escalante 2012). This is a site where endemic Bacillus (Alcaraz, Olmedo, Bonilla 2008;

113 Cerritos, Eguiarte, Avitia 2011), Pseudomonas (Escalante, Caballero-Mellado, Martinez-Aguilar

114 2009) and Exiguobacterium (Rebollar, Avitia, Eguiarte 2012) have been described. Particularly,

115 within the CCB, the Churince System has been studied with more intensity by a large team of

116 scientists since it is the most endangered hydrological system due to its relatively high altitude

117 within the valley (730 $\mathrm{m}$ above sea level, compared to, ca. $700 \mathrm{~m}$ above sea level which is the

118 average of most of the CCB), and because the San Marcos Sierra near this site of the basin is too

119 step to efficiently recharge the aquifer locally. Hence, the system depends mostly on deep

120 ancient water with a magmatic influence (Wolaver, Crossey, Karlstrom 2012). This, together

121 with the calcium sulfate soil matrix, and extreme oligotrophy in terms of phosphorus-limitation

122 (Elser, Schampel, Garcia-Pichel 2005), makes Churince the most unusual site within the CCB 
123 (Minckley \& Cole 1968). This analysis is relevant not only for understanding the extensive

124 biodiversity of this bacteria in such a peculiar environment, but also, for allowing us the

125 biological material for the elucidation of biochemical strategies for survival in conditions of

126 scarcity, future experimentation of bioactive molecules, as well as studies of ecological

127 interactions, including cooperation and competition analyses to understand the processes that are

128 relevant to structure these complex bacterial communities. In contrast to what is commonly

129 expected in an extremely oligotrophic site, we found high morphological and unique taxonomic

130 diversity of culturable Actinobacteria, and we were able to isolate enriched abundance of the

131 genus Streptomyces. When compared to available databases, we observed six novel

132 monophyletic clades and seven single-member clusters, containing a total of 31 OTUs of the

133 genus Streptomyces that are presumably different from other species previously described, and

134 thus, good candidates for consideration as endemic to the CCB. These unique groups of

135 Streptomyces strains represent key clades in evolutionary history of an anciently divergent

136 Phylum of the Bacteria domain.

MATERIALS AND METHODS

Study Site and Sampling

140 The Churince hydrological system (Figure 1) is located in the western part of the CCB, at $740 \mathrm{~m}$

141 above sea level, surrounded by large and mostly pure gypsum dunes. This system consists of

142 three main zones connected by small water causeways: a spring, an Intermediate Lagoon (IL),

143 and a desiccation lagoon (Lopez-Lozano, Heidelberg, Nelson 2013). The Intermediate Lagoon

144 (IL), where sampling took place, has low seasonal variations such as: salinity ranging 1.5-

$1457.1 \mathrm{ppt}, \mathrm{pH} 7.6$ to 8 , and water temperature fluctuation from $14-20{ }^{\circ} \mathrm{C}$ in winter and 20 to $30{ }^{\circ} \mathrm{C}$

146 in summer (data of this study). 

2013, October 2013, October 2014, January 2015, February 2015, July 2015, April 2016.

Samples were obtained from water and upper layer sediment from six locations along the shore

150 in the Intermediate Lagoon in the Churince system (Figure 1) in Cuatro Cienegas, Coahuila with

151 the permission of Federal authorities to collect in the Natural Protected Area (SEMARNAT

152 scientific sampling permit No. SGPA/DGVS/03121/15): Location A: $26^{\circ} 50^{\prime} 53.79^{\prime \prime} \mathrm{N}$,

$153102^{\circ} 08^{\prime} 30.29^{\prime \prime} \mathrm{W}$; location B: $26^{\circ} 50^{\prime} 53.53^{\prime \prime} \mathrm{N}, 102^{\circ} 08^{\prime} 31.81^{\prime \prime} \mathrm{W}$; location $\mathrm{C}: 26^{\circ} 50^{\prime} 54.37^{\prime \prime} \mathrm{N}$,

$154102^{\circ} 08^{\prime} 32.96^{\prime \prime} \mathrm{W}$; location D: $26^{\circ} 50^{\prime} 55.30^{\prime \prime} \mathrm{N}, 102^{\circ} 08^{\prime} 33.63^{\prime \prime} \mathrm{W}$; location E: $26^{\circ} 50^{\prime} 55.63^{\prime \prime} \mathrm{N}$,

$155102^{\circ} 08^{\prime} 35.28^{\prime \prime} \mathrm{W}$; location $\mathrm{F}: 26^{\circ} 50^{\prime} 56.57^{\prime \prime} \mathrm{N}, 102^{\circ} 08^{\prime} 36.03^{\prime \prime} \mathrm{W}$. At each site, water and surface

156 sediments $(0.2-1 \mathrm{~cm})$ were transferred to sterile conical tubes $(50 \mathrm{~mL})$. Samples were transported

157 to a nearby laboratory in the town of Cuatro Cienegas at room temperature $(\leq 1.5 \mathrm{~h})$ and were

158 used for streaking out primary plates immediately.

160 Selective isolation of culturable Actinobacteria

161 Nine selective Actinobacterial Isolation Media (AIM) were designed for this work to enhance the 162 isolation of actinobacteria of aquatic and sediment environment. AIM1 ([per liter]: $21 \mathrm{~g}$ yeast 163 extract agar, 10g Malt extract, 4g Dextrose, 25g Reef salt mix); AIM2 ([per liter]: 20g mannitol, $16420 \mathrm{~g}$ soy flour, 20g Agar, 25g Reef salt mix); AIM3 ([per liter]: 50g chitin, 16g agar, 25g Reef 165 salt mix); AIM4 ([per liter]: 10g starch, $1 \mathrm{~g}$ Casein, 15g agar, 25g Reef salt mix); AIM5 ([per 166 liter]: 20g Oat meal, 0.001g $\mathrm{Fe}_{2}\left(\mathrm{SO}_{4}\right)_{3}, 0.001 \mathrm{~g} \mathrm{MgCl}_{2}, 0.001 \mathrm{~g} \mathrm{ZnSO}$, $18 \mathrm{~g}$ agar, $25 \mathrm{~g}$ Reef salt 167 mix ); AIM6 [per liter]: $10 \mathrm{~g}$ starch, $1 \mathrm{~g} \mathrm{~K}_{2} \mathrm{HPO}_{4}, 1 \mathrm{~g} \mathrm{H}_{14} \mathrm{MgO}_{11} \mathrm{~S}, 2 \mathrm{~g} \mathrm{H}_{8} \mathrm{~N}_{2} \mathrm{O}_{4} \mathrm{~S}, 1 \mathrm{~g} \mathrm{NaCl}, 2 \mathrm{~g}$ $168 \mathrm{CaCO}_{3}, 0.001 \mathrm{~g} \mathrm{FeH}_{14} \mathrm{O}_{11} \mathrm{~S}, 0.001 \mathrm{~g} \mathrm{MgCl}_{2}, 0.001 \mathrm{~g} \mathrm{Z}_{\mathrm{n}} \mathrm{SO}_{4}, 20 \mathrm{~g}$ agar, $25 \mathrm{~g}$ Reef salt mix); AIM7 169 ([per liter]: 40g Soy Tripticasein agar, 25g Reef salt mix ); AIM8 ([per liter]: 10g Bactopeptone, 
170 5g Yeast extract, 16g agar, 25g Reef salt mix ); AIM9 ([per liter]: 100 $\mu 1$ humic acid, $0.02 \mathrm{~g}$

$171 \mathrm{CaCO} 3,0.5 \mathrm{~g}$ Na2HPO4, $0.5 \mathrm{~g} \mathrm{MgSO} 4,1.7 \mathrm{~g} \mathrm{KCl}, 0.01 \mathrm{~g}$ FeSO4, 0.5 mg Vitamin B12, $18 \mathrm{~g}$

172 agar, 25g Reef salt mix).

173 All isolation media were autoclave-sterilized and supplemented with $0.20 \mu \mathrm{m}$ pore size

174 filtered Nystatin $(100 \mu \mathrm{g} / \mathrm{ml})$ to inhibit fungal growth, nalidixic acid $(50 \mu \mathrm{g} / \mathrm{ml})$ to inhibit gram-

175 negative bacteria growth and to favor the growth of slow-growing Actinobacteria.

Prepared media were used for primary selective isolation of Actinobacteria by plating 150

$177 \mu$ directly from fresh samples, and using sterile $3 \mathrm{~mm}$ glass beads. Inoculated plates were

178 incubated at $27 \mathrm{C}$ for 1-6 weeks. Isolates were selected based on colony morphology and Gram

179 stain, picked and re-streaked several times to obtain pure cultures. Isolates were maintained on

180 AIM1 and AIM6 agar plates for short-term storage, and long-term strain collections were set up

181 in $50 \%$ glycerol and preserved at $-20^{\circ} \mathrm{C}$ (sporulated) and $-80^{\circ} \mathrm{C}$ (non-sporulated).

\section{Nucleic acid extraction}

183 To confirm Actinobacteria identity and further phylogenetic analysis of isolates, after testing several techniques, genomic DNA was prepared using a modified phenol/ chloroform method that yielded the best quality DNA for our isolates: colonies of putative Actinobacteria were carefully scraped from agar plates and placed in centrifuge tubes; cell pellets were washed $2 \times$ $10 \mathrm{~mL}$ of $10 \%(\mathrm{w} / \mathrm{v})$ with sucrose and resuspended in $400 \mu \mathrm{l}$ of lysis solution (4\% Triton $\mathrm{x}-100$, $20 \% \mathrm{SDS}, 5 \mathrm{M} \mathrm{NaCl}, 2 \mathrm{M}$ Tris-HCl pH 8, 500mM EDTA pH 8). After resuspension, $400 \mu \mathrm{l}$ of

Phenol/Chloroform and $0.1 \mathrm{~mm}$ glass beads were added to lysis mix and this was mechanically disrupted for 2 minutes. The lysates were centrifuged (12,000 x rpm, $15 \mathrm{~min})$ and DNA in aqueous phase was precipitated with 2 volumes of ethanol and 1/10 volume of $3 \mathrm{M}$ sodium 
192 acetate, $\mathrm{pH} 5.2$; after overnight incubation at $-20^{\circ} \mathrm{C}$, DNA was centrifuged $(12,000 \mathrm{x} \mathrm{rpm}, 10$

193 min at $4^{\circ} \mathrm{C}$ ), washed with $70 \%$ ethanol and eluted in TE with RNase.

194 Molecular Identification and Phylogenetic Analysis

195 Genomic DNA from putative Actinobacteria was sent to Macrogen, Inc., USA, to perform 16S

rDNA gene amplification by PCR and sequencing using the universal primers 27F (5'-

197

198

199

200

201

202

203

204

205

206

207

208

209

210

211

212

213

GAGTTTGATCCTGGCTCAG-3') and 1492R (5'-TACGGYTACCTTGTTACGACTT-3'), as well as phylum-specific primers: S-C-Act-235-a-S-20 (5'CGCGGCCTATCAGCTTGTTG-3') (Stach, Maldonado, Ward 2003) and 23SR (5'-AGGCATCCACCGTGCGCCCT3') (Yoon, Lee, Kim 1997).

The 16S rDNA gene sequences were edited and assembled using CodonCode Aligner 5.1 software (CodonCode Corporation, Dedham, MA); assembled contigs were compared to $16 \mathrm{~S}$ rDNA gene sequences in the NCBI database (http: //www.ncbi.nlm.nih.gov/) using the Basic Local Alignment Search Tool (BLAST) to determine genus-level affiliations and are deposited in GenBank, which is associated with this document and are also available as Supplementary Material.

Our 16S rDNA gene sequences sharing a phylogenetic affiliation with Actinobacteria and reference sequences were aligned with ClustalW (Higgins 1994) using Molecular Evolutionary Genetics Analysis MEGA Version 7 (Kumar, Stecher \& Tamura 2016).

Phylogenetic reconstructions were performed to analyze CCB OTUs clustering and taxonomic identification of the isolates in an evolutionary context. The phylogenetic tree of total Actinobacterial isolates was constructed by Maximum Likelihood (ML) algorithm using MEGA software v. 7 (Kumar, Stecher \& Tamura 2016) and Tamura-Nei I+G (Tamura 1992) parameter 
214 as an evolutionary model with 1,000 replicates. For a more comprehensive interpretation of

215 results, 16S sequences of previously characterized species of Actinobacteria with closest

216 affiliations to our isolates, were obtained from GenBank databases and added to reconstructions

217 of this Phylum. Criteria for selection of reference sequences was based on similarity and length

218 of nucleotide sequences, but also, the selection of $16 \mathrm{~S}$ sequences from study model organisms

219 (such as S. coelicolor) and also microorganisms originally isolated from water and sediments

220 from aquatic environments. Other reference strains were added to provide biological

221 interpretation, and were selected from previous work reporting isolation of Streptomyces from

222 deserts (Okoro, Brown, Jones 2009; Rateb et al., 2011). Model selection was performed using

223 statistical and evolutionary analysis of multiple sequence alignments TOPALi v2 (Milne,

224 Lindner, Bayer 2009).

Abundance and diversity were clearly remarkable for Streptomyces. From these early

226

227

228

229

230

231

232

233

234

235

236

observations, we decided to compare distances between our Streptomyces isolates, to available information from previous studies, so we included a dataset of 667 16S-rDNA sequences of validated species of Streptomyces; most of them were selected for a wide phylogenetic analysis within the family (Labeda, Goodfellow, Brown 2012; Labeda, Dunlap, Rong 2017). We first performed a phylogenetic reconstruction using parameters and conditions reported by Labeda, et. al., 2012. Obtaining a preliminary Neighbour Joining (NJ) tree and leading us to the identification of relevant information regarding evolutionary relationships as well as the extent of the isolated diversity. It also provided criteria for selection of ideal reference strains for a later, more stringent analysis.

To reconstruct a second phylogenetic tree of the members of family Streptomycetaceae, we used the Maximum-likelihood (ML) method using MEGA software v. 7 and the Tamura-Nei 
237 I + G parameter as an evolutionary model. The reliability of nodes was estimated by ML

238 bootstrap percentages (Felsenstein 1985) obtained after 1,000 replications. A total of $4116 \mathrm{~S}$

239 sequences obtained in this study were included, and 73 reference strains belonging to the genera

240 Streptomyces, 6 of Kitasatospora and 3 Streptoacidophilus, which were the most closely related

241 to our isolates, were selected (trimmed to $1074 \mathrm{bp}$ ).

242 To provide support to ML tree, we conducted a Bayesian analysis employing MrBayes v3.2.5

243 (Ronquist, Teslenko, van der Mark 2012) with 10,000,000 Markov chain Monte Carlo

244 generations and the GTR $+\mathrm{G}$ model of evolution with a nucmodel $=4$ by 4 , nruns $=2$, nchains $=4$,

245 and sampled freq $=100$. The average standard deviation of split frequences was below 0.001 .

246 The nodes that had posterior probabilities greater than $95 \%$ (Bayesian), were considered well-

247 supported and were shown in the resulting tree.

248

249 Estimation of diversity of Actinobacteria in CCB

250 To estimate species richness in the IL in the Churince system, we performed a rarefaction

251 analysis for total Actinobacteria isolates, and another for only Streptomyces isolates. The

252 definition of operational taxonomic units (OTUs) was conducted with MEGA software v. 7 at

$25397 \%$ cutoff according to their pairwise distances. Then we conducted the rarefaction curve using

254 the EstimateS 9.1.0 software package (Colwell \& Elsensohn 2014) at the 95\% confidence level.

255

256

257 RESULTS

258 Diversity of culturable Actinobacteria within the Churince system in CCB 
A total of 350 morphologically and nutritionally diverse isolates were successfully cultured and characterized as members of the Phylum Actinobacteria throughout the three-year period. AIM2 and AIM4 were the best nutrient conditions for culturing Actinomycetes (Figure the most abundant taxa, accounting for over $50 \%$ of total sequenced isolates. Churince. Among all sampling sites, $\mathrm{C}$ was the location where we found the highest diversity and abundance of Streptomyces strains. Only Streptomyces was ubiquitous in Churince IL and through the seasons, while isolation of the other 10 genera showed fluctuations.

From the entire isolated collection, 105 strains were successfully subcultured, processed the order Actinomycetales, and to suborders Corynebacterineae, Pseudonocardineae, Streptosporangineae, Frankineae, Streptomycineae, Micromonosporineae, Glycomycineae, and Micrococcineae, encompassing 11 genera of Actinobacteria. For phylogenetic analysis, a radial tree is presented in supplementary material (Supp. Fig.1) showing the extent of macrodiversity of the genera of Actinobacteria retrieved from CCB. taxonomic levels (Actinobacteria phylum and Streptomyces genus) is large (Figure 3) in fact, far higher than the 30 and 12 OTUs for Actinobacteria and Streptomyces respectively, defined with

279 a 97\% cutoff according to their pairwise distances of the 16S-rDNA sequences, as seen by the curves, which are far from reaching the asymptote. 
282 High diversity and phylogenetic clustering of Streptomyces from Cuatro Cienegas.

283

284

285

286

287

288

289

290

291

292

293

294

295

296

297

298

299

300

301

302

303

304
Primary isolation plates were enriched with Streptomyces-like colonies in every sampling culture, with characteristic morphologies and geosmin-like odor. Streptomyces isolates account for $54 \%$ of the total sequenced isolates and since this genus was the most abundant in all media, sampling site and season, we first characterized these isolates based on their morphology to avoid picking clonal individuals for later DNA sequencing. Morphologies and other culturerelated phenotypes varied among all selected individuals throughout the process of subculturing, such as colony morphology, pigment production, colony sporulation, optimal growth temperature and growth rate. Some of the different colony morphologies in Streptomyces are shown in Figure 4.

A preliminary phylogenetic reconstruction of the family Streptomycetaceae was performed using isolates from this study and a dataset of 667 16S-rDNA sequences from Streptomyces previously used for a broad phylogenetic analysis within the family Streptomycetaceae (Labeda et al., 2012) (Supplementary Material Fig. 2). The analysis shows that numerous $\mathrm{CCB}$ isolates are closer to each other and separated along the tree topology from most reference organisms. To construct a summarized and well-supported phylogenetic analyses, two different methods were used (Bayesian and ML), including 95 close reference strains, as well as sequences from isolates from the Atacama Desert and other ecologically similar isolates (Figure 5). In this summarized analysis, we can unambiguously identify six novel monophyletic clades with 31 new OTUs and 7 single-member clusters, all of them isolated in the present study.

\section{DISCUSSION}

\section{Actinobacteria from oligotrophic $C C B$ are diverse and abundant.}


this effort, 350 morphologically diverse isolates of Actinobacteria within the Churince system,

308

309

310

311

312

were successfully cultured making a large, valuable, indigenous collection of different cultivated morphologies within one particular site. Nevertheless, due to well-known difficulties in genotyping this phylum (Yoon et al., 1997; Stach et al., 2003; Farris \& Olson 2007; Kumar, Aiemsum-Ang, Ward 2007), we were able to extract DNA and sequence 16S-rDNA of only 105 of them. In light of our observations of the abundance and uniqueness of the 16S sequence of the Streptomyces from the CCB and the reported biases from other studies in Actinobacteria (Hansen, Tolker-Nielsen, Givskov 1998; Farris \& Olson 2007; Krogius-Kurikka, Kassinen, Paulin 2009; Rajendhran \& Gunasekaran 2011), it is not difficult to speculate that this group of microorganisms would require a different approach for a detailed characterization, such as whole-genome analysis of culturable strains. Ongoing work in our research group is applying this strategy for the most peculiar strains of our collection.

Although gram-positive bacteria are more commonly observed in organic rich habitats (Fenical 1993), isolated strains from the extremely oligotrophic Churince IL encompass 11 genera of Actinobacteria (Figure 2), which is comparable to the culturable diversity found in rich marine environments (Duncan et al., 2015; Duran et al., 2015; Kuang et al., 2015; Chen et al., 2016; Undabarrena et al., 2016). Interestingly, Streptomyces was the most abundant taxa, representing over $50 \%$ of the total sequenced isolates varying in relation to sampling point within the Churince system (figure 2). This result is comparable to the Streptomyces-enriched isolation in extreme environments such as the Atacama Desert (Okoro et al., 2009), nonetheless CCB culturable diversity within the Phylum Actinobacteria is greater. 
CCB culturable Streptomyces diversity is still far from being exhaustively explored as

329

shown by rarefaction analysis (figure 3), suggesting a complex community structure, both in sediment and in the water column.

Morphological and genetic diversity of this phylum in the Churince does not come totally as a surprise since in concurrent studies using Illumina16S rRNA tags (Souza et al., in review) it was observed that Actinobacteria are the most successful lineage in CCB water, with notable presence of genera Streptomyces, Yaniella, Arthrobacter, Trueperella, as well as several putative Actinobacteria from non-culturable marine lineages, in particular a strain closely related to the marine PeM15, which is very sensitive to nutrient enrichment (Lee et al., submitted) and other clades unique to soil and sediment. These analyses are consistent with our isolation efforts, which yielded abundant and diverse Streptomyces and abundant Arthrobacter isolates. It is possible to speculate that those several putative non-culturable Actinobacteria lineages detected by Illumina in concurrent projects, relate to our great numbers of cultured isolates which were not able to be detected by universal and phylum-specific primers.

Many interesting morphotypes could not be identified using 16S rDNA sequences, and in addition, many were lost as the purification of a single colony proceeded. Success at bringing the environment into the laboratory culture is not sufficient for successful cultivability of bacteria.

Subsequent culturing of Actinomycetes to obtain axenic (pure) cultures from the Churince, dramatically reduced the total number of unique pure isolates, suggesting obligate mutualism and cross-feeding (Tanaka, Hanada, Manome 2004; Kim, Kim, Masui 2011; Seth \& Taga 2014). It is quite interesting to observe that previous bacterial isolation efforts in the IL of the Churince in the CCB, using a culture-dependent approach initially based on thermo-resistant aquatic strains, did not lead to the isolation of Streptomyces individuals among the numerous 
351 isolated Actinobacteria (Cerritos et al., 2011). Many variables can play a role in this marked

352 difference, most probably the different culture methods of Cerritos et al. (2011) through which

353 thermoresistant bacteria in Marine Agar media were selected, thus enriching the isolation of

354 Micrococcineae members. In contrast, our study applied several media with different carbon and

355 nitrogen sources to maximize the possibility of culturing a wider diversity. Even so, the

356 rarefaction curve shows that the potentially yet-to-be-cultured diversity is large (Figure 3), as

357 commonly occurs in highly diverse communities (Colwell, Mao \& Chang 2004; Colwell \&

358 Elsensohn 2014).

359 Another possible factor that could explain differences between our study and Cerritos et

360 al. (2011) is the years which passed between sampling periods, including possible temporal

361 variation in the community structure. Notably in the CCB, after the time of the initial isolations

362 described in Cerritos et al. (2011), a decline of the Churince aquifer occurred. As shown in

363 experiments with UV and temperature increase in mesocosms (Pajares, Eguiarte, Bonilla-Rosso

364 2013; Pajares, Souza \& Eguiarte 2015), endemic CCB Actinobacteria are particularly susceptible

365 to perturbation. Hence, it is possible that enrichment of Streptomyces after 2010 is a succession

366 response to the shrinkage and concomitant changes in the Churince aquifer system.

367

368 Endemicity of Streptomyces in CCB

369 As expected from previous studies finding endemic microorganisms at CCB (Alcaraz et al.,

370 2008; Rebollar et al., 2012), we found 38 unique operational taxonomic units (OTU's) for

371 Streptomyces. Moreover, these 38 novel OTUs are in six new monophyletic clades in a deeply

372 represented and well-supported phylogeny of the family Streptomycetaceae, which is a sign of

373 endemicity. What makes this result unprecedented in a relatively very well-known cosmopolitan 
374 genus, Streptomyces (Barka et al., 2016), is the discovery of this degree of diversity and

375 endemism in such an oligotrophic extreme environment.

376 Even though these data do not represent evidence of dispersal limitation per se, the phylogenetic

377 clustering of OTUs of the CCB among themselves, and the genetic distance between OTUs from

378667 reported species of Streptomycetaceae family from other sites around the world (Fig. 5 and

379 Supplementary Fig. 2), could be explained by migration limitation to and out of the CCB.

380

381

382

383

384

385

386

387

388

389

390

391

392

393

394

395

396

\section{Relevance of culturing new Actinobacteria strains and lineages}

Only a tiny fraction of the universal bacterial diversity has been pure cultured (Pace 2009), and with this, the description of the biological diversity of the prokaryotic branch of the tree of life remains limited. Moreover, as culturable Actinobacteria diversity available for the study and characterization has been still insufficient when searching for bioactive compounds, there has been an increasing urge to culture untapped diversity within under-explored habitats (Katz \& Baltz 2016).

While genome mining represents a major paradigm shift for exploration of rare taxa (Cano-Prieto, Garcia-Salcedo, Sanchez-Hidalgo 2015; Tang, Liu, Peng 2015; Iftime, Kulik, Hartner 2016; Smanski, Schlatter \& Kinkel 2016), recent studies from genome mining for secondary metabolites gene clusters of unculturable Actinobacteria support the culturable approach for natural product discovery targeting "gifted microbes", obtaining samples from unexplored habitats. In particular, untapped marine sediments are recommended when searching for cultivable potentially bioactive natural products from Actinobacteria (Baltz 2016).

Although clades and clusters of CCB-isolates along the phylogeny might suggest that OTUs within the same groups are very close to each other, figure 4 shows distinctive 
397 morphologies that clearly reflect the uniqueness of each isolate. Hence, this collection of

398 Actinobacteria from Cuatro Cienegas represents an invaluable source of great diversity for

399 microbial ecology and biotechnology studies considering that: $i$ ) phylogenies constructed with

400 the sequenced portion of our collection indicate six novel clades of Streptomyces, but they only

401 represent a third of the successfully cultured collection; ii) this collection has been isolated from

402 an environment of a diversity and endemicity, that has previously been considered comparable to

403 that in the Galápagos Island (Souza et al., 2012), and as revealed by our six clades cointaining

404 only CCB isolates (Fig. 5), it is quite likely that we have cultured several unique species yet to be

405 described; iii) the great diversity shown here has been calculated using the conserved 16S rDNA

406 marker, but it is well known that single-gene phylogenies might not always reflect the

407 evolutionary history of a species due to the high degree of horizontal gene transfer (Marri, Hao

408 \& Golding 2006), a phenomenon particularly common in Streptomyces (Huguet-Tapia, Lefebure,

409 Badger 2016; Tian, Zhang, Yang 2016).

410 In conclusion, we can mention that our findings suggest a very high, albeit still

411 uncalculated richness in microbial diversity in CCB, as well as suggested endemism. Our main

412 result show that the CCB is not only a special place to study community structure where

413 Actinobacteria diversity plays a major ecological role in such an oligotrophic environment, but it

414 also represents a promising area for bioprospecting studies that will require concerted long-term

415 efforts to search for genuine and substantial contributions to the discovery of natural products. 


\section{FIGURES}
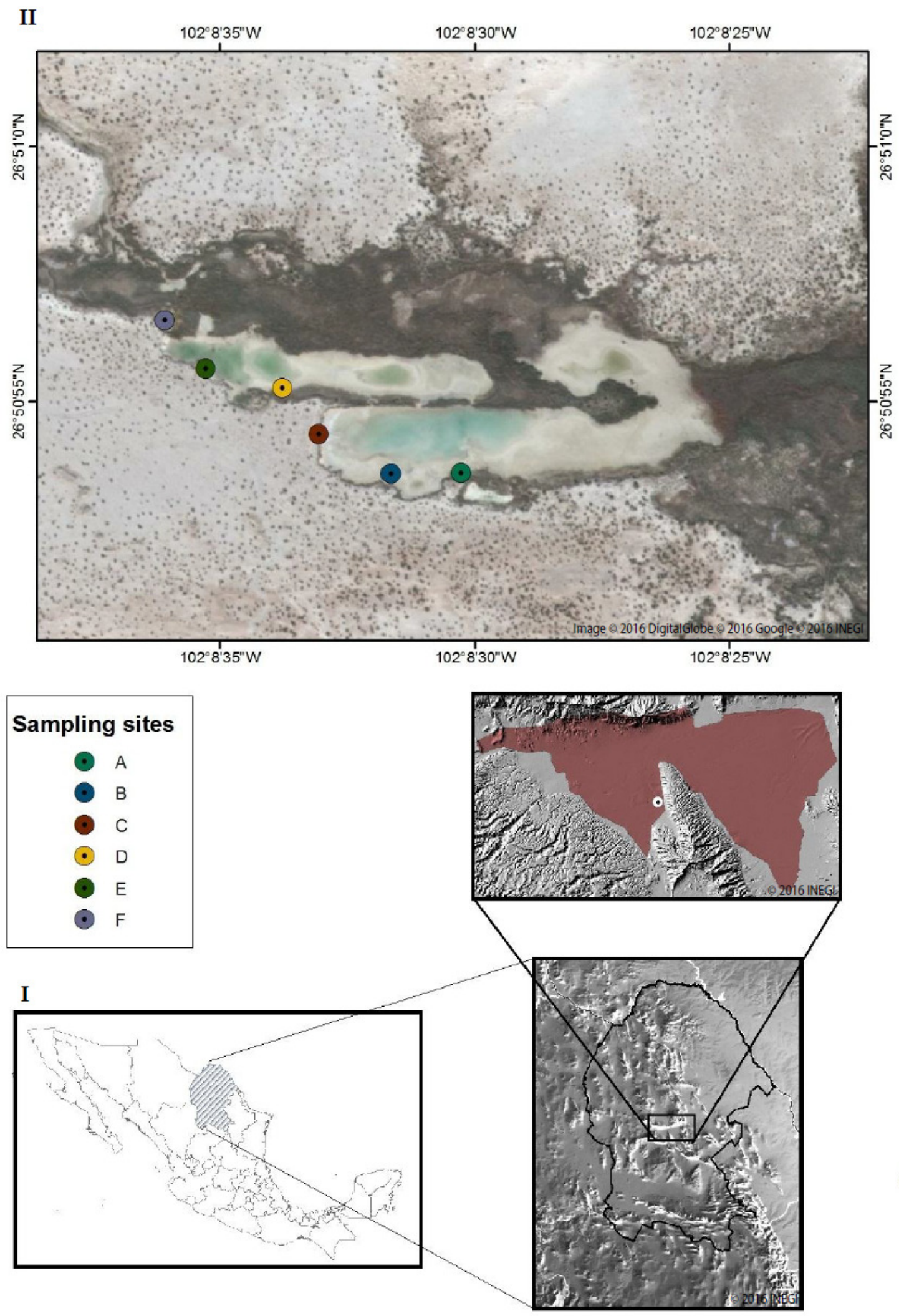

$\uparrow$ 
422 Figure 1. The Churince hydrological system. (I) Map of Mexico displaying the State of Coahuila 423 and the location of the Cuatro Cienegas Basin (CCB) and the Churince hydrological system

424 (circle) (C) 2016 INEGI. (II) Aerial view of the intermediate lagoon (IL) in the Churince

425 hydrological system. The circular forms point out the sampling sites. Image (C) 2016

426 DigitalGlobe (C) 2016 Google (C) 2016 INEGI.

427

428

429

430

431

432

433

434

435

A

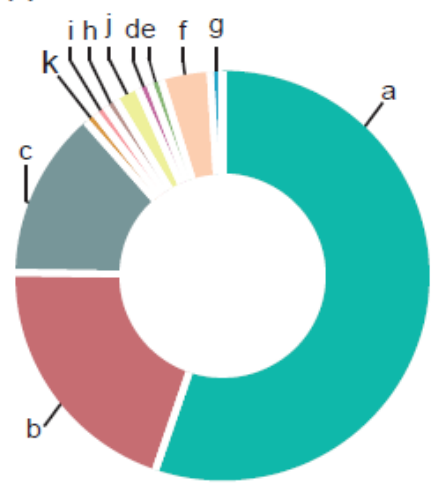

a Streptomyces 54\% b Nocardia 20\%

f Arthrobacter 3\% g Kocuria 1\%

436

437

438

439

440
B

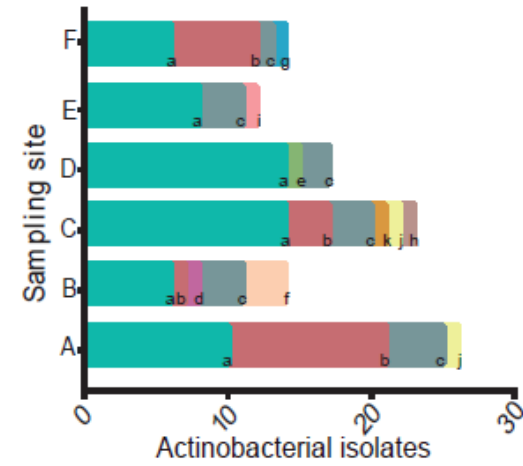

Actinobacterial isolates

c Nocardiopsis $15 \%$

h Microbacterium $1 \%$
C

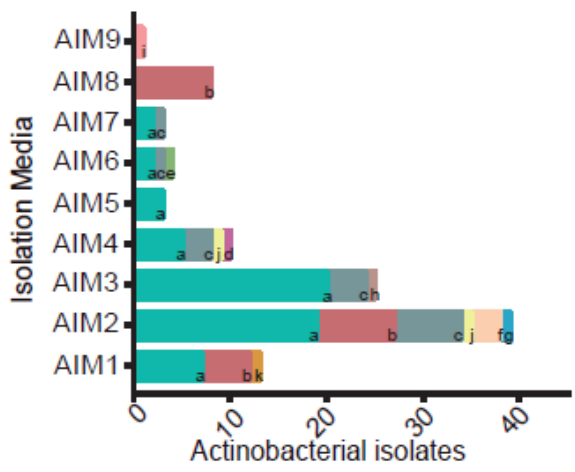

Glycomyces $1 \%$ Verrucosispora1\%

Blastococcus 1\% 


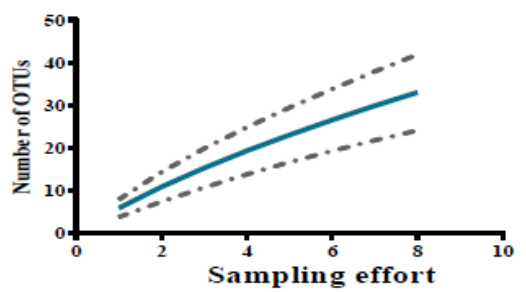

B

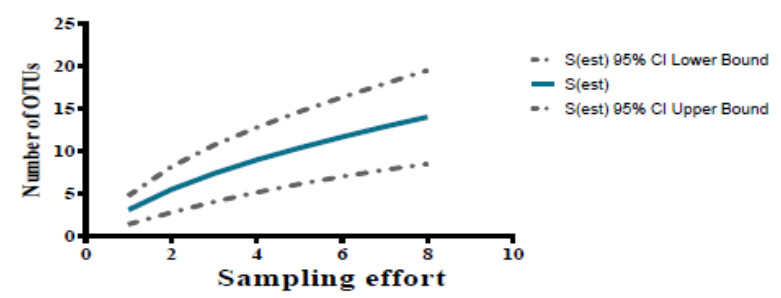

444 Figure 3. Rarefaction curves show sampling effort on the estimation of the numbers of OTUs at $44597 \%$ sequence identity from cultured Actinobacteria (A), and total isolated Streptomyces (B) 446 from CCB.

447

448

449

450

451
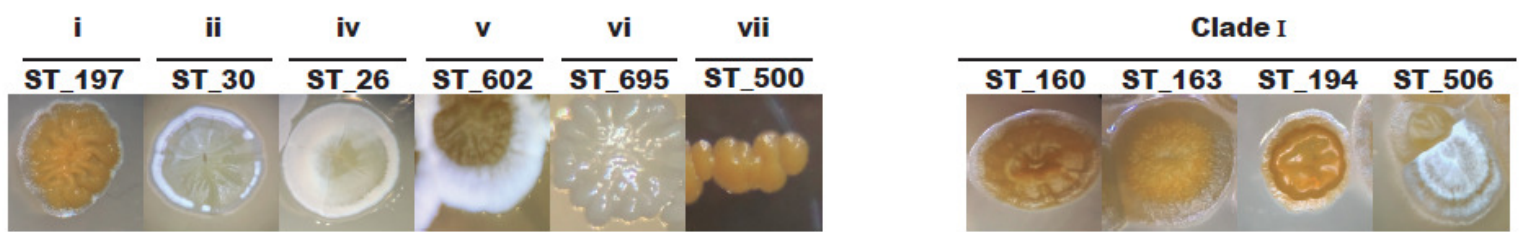

Clade II

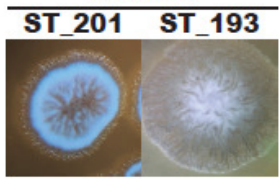

Clade $\mathrm{V}$

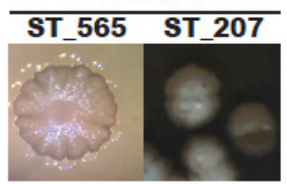

Clade III
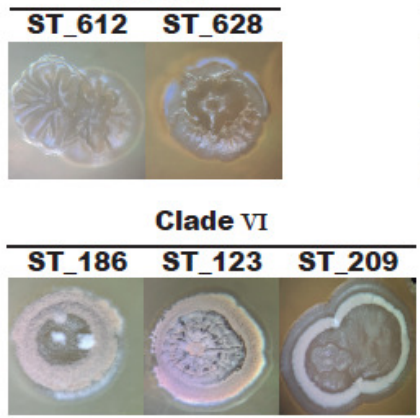

Clade IV

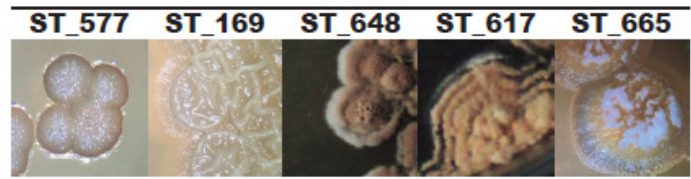

Non CCB clades

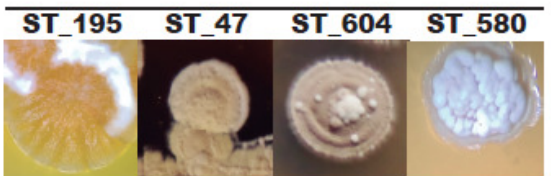

453 Figure 4. Colony morphological diversity of Streptomyces isolated from CCB within clades. 


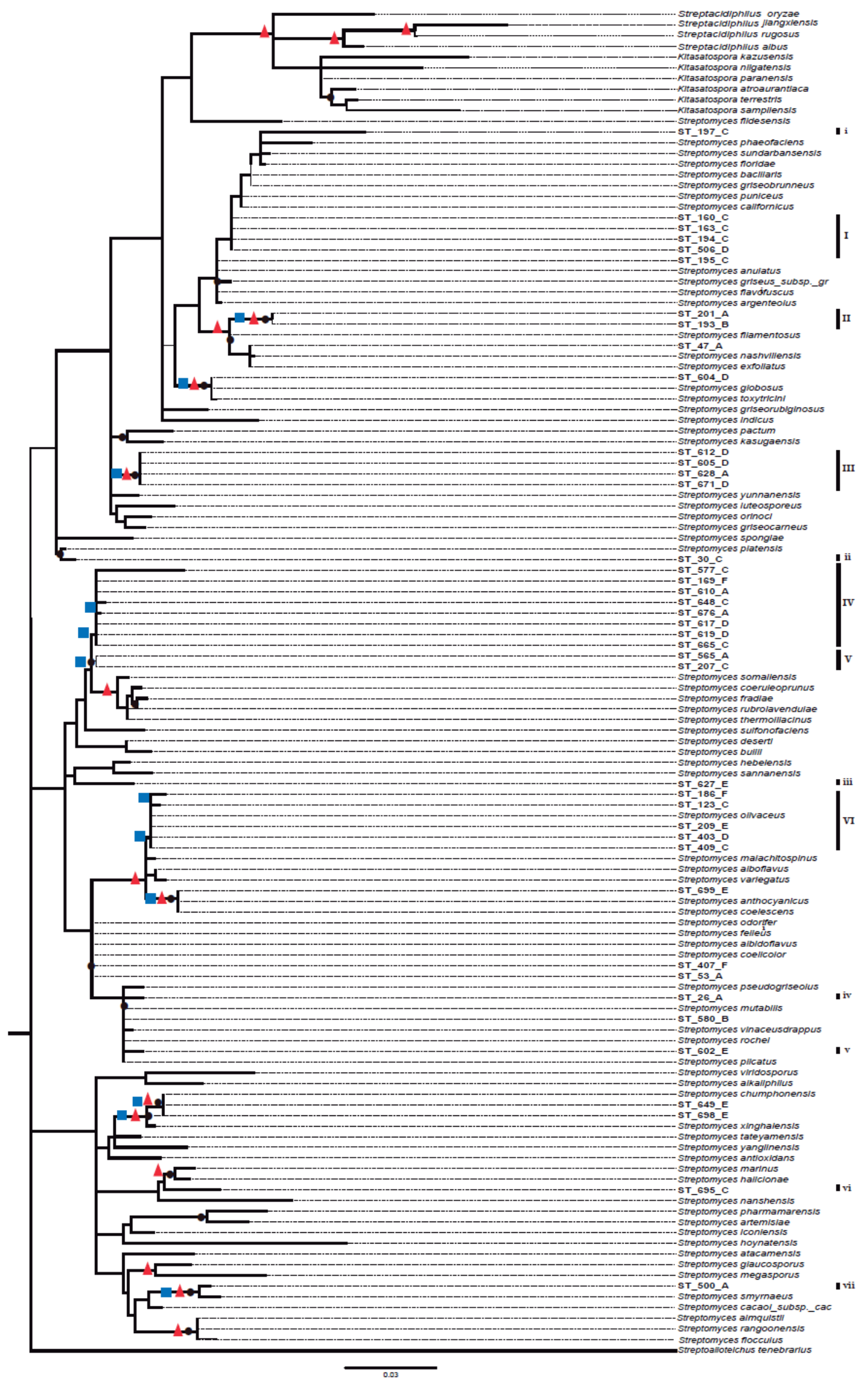

PeerJ reviewing PDF | (2016:12:15173:1:1:NEW 24 Mar 2017) 
455 Figure 5. Phylogenetic tree of Streptomycetaceae family based on nearly full-lenght 16s rRNA 456 gene sequences and their closely related type strains based on the maximum likelihood (ML) 457 method, constructed by Tamura-Nei I + G evolutionary model with 1000 bootstrap replicates. 458 Bootstrap values for ML in the range from 0.7 to 1 were marked with black circles. Bayesian 459 supports at nodes in ranges 0.95 to 1 were marked with a red triangles and Bootstrap values for 460 neighbor-joining at ranges 0.6 to 1 in blue squares.

461

462

463

\section{Acknowledgements}

464

We thank Hamlet Avilés Arnaut for his critical review of the manuscript and Gabriela Olmedo

465

466

467

468

469

470

471

472

473

474

475

476

477

478

479

480 for her invaluable support and critical observations throughout the project. We also want to thank

Mercedes Cortés for her assistance during microbiological work with the Streptomyces

collection. We deeply acknowledge "Centro de Bachillerato Tecnológico Agropecuario \#22” for providing facilities during the sampling period. Finally, we thank

SEMARNAT for access to and permission to sample in the CCB Natural Protected Area 
481

482

483

484

485

486

487

488

489

490

491

492

493

494

495

496

497

498

499

500

501

502

503

504

505

506

507

508

509

510

511

512

513

514

515

516

517

518

519

520

521

522

523

524

525

526

527

528

529

\section{Bibliography}

Alcaraz, L. D., G. Olmedo, G. Bonilla, R. Cerritos, G. Hernandez, A. Cruz, E. Ramirez, C. Putonti, B. Jimenez, E. Martinez, V. Lopez, J. L. Arvizu, F. Ayala, F. Razo, J. Caballero, J. Siefert, L. Eguiarte, J. P. Vielle, O. Martinez, V. Souza, A. Herrera-Estrella and L. Herrera-Estrella (2008). "The genome of Bacillus coahuilensis reveals adaptations essential for survival in the relic of an ancient marine environment." Proc Natl Acad Sci U S A 105(15): 5803-5808 DOI: 10.1073/pnas.0800981105. Allen, M. A., F. Goh, B. P. Burns and B. A. Neilan (2009). "Bacterial, archaeal and eukaryotic diversity of smooth and pustular microbial mat communities in the hypersaline lagoon of Shark Bay." Geobiology 7(1): 82-96 DOI: 10.1111/j.1472-4669.2008.00187.x.

Andam, C. P., J. R. Doroghazi, A. N. Campbell, P. J. Kelly, M. J. Choudoir and D. H. Buckley (2016). "A Latitudinal Diversity Gradient in Terrestrial Bacteria of the Genus Streptomyces." MBio 7(2): e0220002215 DOI: 10.1128/mBio.02200-15.

Antony-Babu, S., J. E. Stach and M. Goodfellow (2008). "Genetic and phenotypic evidence for Streptomyces griseus ecovars isolated from a beach and dune sand system." Antonie Van Leeuwenhoek 94(1): 63-74 DOI: 10.1007/s10482-008-9246-y.

Avitia, M., A. E. Escalante, E. A. Rebollar, A. Moreno-Letelier, L. E. Eguiarte and V. Souza (2014). "Population expansions shared among coexisting bacterial lineages are revealed by genetic evidence." PeerJ 2: e696 DOI: 10.7717/peerj.696.

Baltz, R. H. (2016). "Gifted microbes for genome mining and natural product discovery." J Ind Microbiol Biotechnol DOI: 10.1007/s10295-016-1815-x.

Barka, E. A., P. Vatsa, L. Sanchez, N. Gaveau-Vaillant, C. Jacquard, H. P. Klenk, C. Clement, Y. Ouhdouch and G. P. van Wezel (2016). "Taxonomy, Physiology, and Natural Products of Actinobacteria." Microbiol Mol Biol Rev 80(1): 1-43 DOI: 10.1128/MMBR.00019-15. Cano-Prieto, C., R. Garcia-Salcedo, M. Sanchez-Hidalgo, A. F. Brana, H. P. Fiedler, C. Mendez, J. A. Salas and C. Olano (2015). "Genome Mining of Streptomyces sp. Tu 6176: Characterization of the Nataxazole Biosynthesis Pathway." Chembiochem 16(10): 1461-1473 DOI: 10.1002/cbic.201500153. Cerritos, R., L. E. Eguiarte, M. Avitia, J. Siefert, M. Travisano, A. Rodriguez-Verdugo and V. Souza (2011). "Diversity of culturable thermo-resistant aquatic bacteria along an environmental gradient in Cuatro Cienegas, Coahuila, Mexico." Antonie Van Leeuwenhoek 99(2): 303-318 DOI: 10.1007/s10482010-9490-9.

Chen, P., L. Zhang, X. Guo, X. Dai, L. Liu, L. Xi, J. Wang, L. Song, Y. Wang, Y. Zhu, L. Huang and Y. Huang (2016). "Diversity, Biogeography, and Biodegradation Potential of Actinobacteria in the Deep-Sea Sediments along the Southwest Indian Ridge." Front Microbiol 7: 1340 DOI: 10.3389/fmicb.2016.01340. Claverias, F. P., A. Undabarrena, M. Gonzalez, M. Seeger and B. Camara (2015). "Culturable diversity and antimicrobial activity of Actinobacteria from marine sediments in Valparaiso bay, Chile." Front Microbiol 6: 737 DOI: 10.3389/fmicb.2015.00737.

Coghill, L. M., C. D. Hulsey, J. Chaves-Campos, F. J. Garcia de Leon and S. G. Johnson (2013).

"Phylogeography and conservation genetics of a distinct lineage of sunfish in the Cuatro Cienegas valley of Mexico." PLoS One 8(10): e77013 DOI: 10.1371/journal.pone.0077013.

Colwell, R. K. and J. E. Elsensohn (2014). "EstimateS turns 20: statistical estimation of species richness and shared species from samples, with non-parametric extrapolation." Ecography 37(6): 609-613 DOI: 10.1111/ecog.00814. Colwell, R. K., C. X. Mao and J. Chang (2004). "Interpolating, extrapolating, and comparing incidencebased species accumulation curves." Ecology 85(10): 2717-2727 DOI: 10.1890/03-0557. Coombs, J. T. and C. M. Franco (2003). "Isolation and identification of actinobacteria from surfacesterilized wheat roots." Appl Environ Microbiol 69(9): 5603-5608.

Davelos, A. L., K. Xiao, D. A. Samac, A. P. Martin and L. L. Kinkel (2004). "Spatial variation in Streptomyces genetic composition and diversity in a prairie soil." Microb Ecol 48(4): 601-612 DOI: 10.1007/s00248-004-0031-9. 
530 Duncan, K. R., B. Haltli, K. A. Gill, H. Correa, F. Berrue and R. G. Kerr (2015). "Exploring the diversity and metabolic potential of actinomycetes from temperate marine sediments from Newfoundland, Canada." J Ind Microbiol Biotechnol 42(1): 57-72 DOI: 10.1007/s10295-014-1529-x.

Duran, R., A. Bielen, T. Paradzik, C. Gassie, E. Pustijanac, C. Cagnon, B. Hamer and D. Vujaklija (2015). "Exploring Actinobacteria assemblages in coastal marine sediments under contrasted Human influences in the West Istria Sea, Croatia." Environ Sci Pollut Res Int 22(20): 15215-15229 DOI: 10.1007/s11356-015-4240-1.

Elser, J. J., J. H. Schampel, F. Garcia-Pichel, B. D. Wade, V. Souza, L. Eguiarte, A. N. A. Escalante and J. D. Farmer (2005). "Effects of phosphorus enrichment and grazing snails on modern stromatolitic microbial communities." Freshwater Biology 50(11): 1808-1825 DOI: 10.1111/j.13652427.2005.01451.x. Escalante, A. E., J. Caballero-Mellado, L. Martinez-Aguilar, A. Rodriguez-Verdugo, A. GonzalezGonzalez, J. Toribio-Jimenez and V. Souza (2009). "Pseudomonas cuatrocienegasensis sp. nov., isolated from an evaporating lagoon in the Cuatro Cienegas valley in Coahuila, Mexico." Int J Syst Evol Microbiol 59(Pt 6): 1416-1420 DOI: 10.1099/ijs.0.006189-0.

Farris, M. H. and J. B. Olson (2007). "Detection of Actinobacteria cultivated from environmental samples reveals bias in universal primers." Lett Appl Microbiol 45(4): 376-381 DOI: 10.1111/j.1472765X.2007.02198.x. Felsenstein, J. (1985). "Confidence Limits on Phylogenies: An Approach Using the Bootstrap." Evolution 39(4): 783-791 DOI: $10.2307 / 2408678$.

Fenical, W. (1993). "Chemical studies of marine bacteria: developing a new resource." Chemical Reviews 93(5): 1673-1683 DOI: 10.1021/cr00021a001.

Gonzalez-Gonzalez, A., L. L. Sanchez-Reyes, G. Delgado Sapien, L. E. Eguiarte and V. Souza (2013). "Hierarchical clustering of genetic diversity associated to different levels of mutation and recombination in Escherichia coli: a study based on Mexican isolates." Infect Genet Evol 13: 187-197 DOI: 10.1016/j.meegid.2012.09.003.

Goodfellow, M. and S. T. Williams (1983). "Ecology of actinomycetes." Annu Rev Microbiol 37: 189-216 DOI: 10.1146/annurev.mi.37.100183.001201.

Gremion, F., A. Chatzinotas and H. Harms (2003). "Comparative 16S rDNA and 16S rRNA sequence analysis indicates that Actinobacteria might be a dominant part of the metabolically active bacteria in heavy metal-contaminated bulk and rhizosphere soil." Environ Microbiol 5(10): 896-907.

Grossart, H. P., A. Schlingloff, M. Bernhard, M. Simon and T. Brinkhoff (2004). "Antagonistic activity of bacteria isolated from organic aggregates of the German Wadden Sea." FEMS Microbiol Ecol 47(3): 387396 DOI: 10.1016/S0168-6496(03)00305-2.

Hansen, M. C., T. Tolker-Nielsen, M. Givskov and S. Molin (1998). "Biased 16S rDNA PCR ampliccation caused by interference from DNA flanking the template region " FEMS Microbiology Ecology 26 141-149.

Higgins, D. G. (1994). "CLUSTAL V: multiple alignment of DNA and protein sequences." Methods Mol Biol 25: 307-318 DOI: 10.1385/0-89603-276-0:307.

Huguet-Tapia, J. C., T. Lefebure, J. H. Badger, D. Guan, G. S. Pettis, M. J. Stanhope and R. Loria (2016). "Genome Content and Phylogenomics Reveal both Ancestral and Lateral Evolutionary Pathways in PlantPathogenic Streptomyces Species." Appl Environ Microbiol 82(7): 2146-2155 DOI: 10.1128/AEM.03504-15.

Iftime, D., A. Kulik, T. Hartner, S. Rohrer, T. H. Niedermeyer, E. Stegmann, T. Weber and W. Wohlleben (2016). "Identification and activation of novel biosynthetic gene clusters by genome mining in the kirromycin producer Streptomyces collinus Tu 365." J Ind Microbiol Biotechnol 43(2-3): 277-291 DOI: $10.1007 / \mathrm{s} 10295-015-1685-7$. Jami, M., M. Ghanbari, W. Kneifel and K. J. Domig (2015). "Phylogenetic diversity and biological activity of culturable Actinobacteria isolated from freshwater fish gut microbiota." Microbiol Res 175: 615 DOI: 10.1016/j.micres.2015.01.009. 
580 Jensen, P. R., R. Dwight and W. Fenical (1991). "Distribution of actinomycetes in near-shore tropical

581

582

583

584

585

586

587

588

589

590

591

592

593

594

595

596

597

598

599

600

601

602

603

604

605

606

607

608

609

610

611

612

613

614

615

616

617

618

619

620

621

622

623

624

625

626

627

628

629 marine sediments." Appl Environ Microbiol 57(4): 1102-1108.

Jensen, P. R. and C. Mafnas (2006). "Biogeography of the marine actinomycete Salinispora." Environ Microbiol 8(11): 1881-1888 DOI: 10.1111/j.1462-2920.2006.01093.x.

Johnson, S. G. (2005). "Age, phylogeography and population structure of the microendemic banded spring snail, Mexipyrgus churinceanus." Mol Ecol 14(8): 2299-2311 DOI: 10.1111/j.1365294x.2005.02580.x.

Katz, L. and R. H. Baltz (2016). "Natural product discovery: past, present, and future." J Ind Microbiol Biotechnol 43(2-3): 155-176 DOI: 10.1007/s10295-015-1723-5.

Kim, K., J. J. Kim, R. Masui, S. Kuramitsu and M. H. Sung (2011). "A commensal symbiotic interrelationship for the growth of Symbiobacterium toebii with its partner bacterium, Geobacillus toebii." BMC Res Notes 4: 437 DOI: 10.1186/1756-0500-4-437.

Kinkel, L. L., D. C. Schlatter, K. Xiao and A. D. Baines (2014). "Sympatric inhibition and niche differentiation suggest alternative coevolutionary trajectories among Streptomycetes." ISME J 8(2): 249256 DOI: 10.1038/ismej.2013.175.

Krogius-Kurikka, L., A. Kassinen, L. Paulin, J. Corander, H. Makivuokko, J. Tuimala and A. Palva (2009). "Sequence analysis of percent $\mathrm{G}+\mathrm{C}$ fraction libraries of human faecal bacterial DNA reveals a high number of Actinobacteria." BMC Microbiol 9: 68 DOI: 10.1186/1471-2180-9-68.

Kuang, W., J. Li, S. Zhang and L. Long (2015). "Diversity and distribution of Actinobacteria associated with reef coral Porites lutea." Front Microbiol 6: 1094 DOI: 10.3389/fmicb.2015.01094.

Kuhn, E., A. S. Ichimura, V. Peng, C. H. Fritsen, G. Trubl, P. T. Doran and A. E. Murray (2014). "Brine assemblages of ultrasmall microbial cells within the ice cover of Lake Vida, Antarctica." Appl Environ Microbiol 80(12): 3687-3698 DOI: 10.1128/AEM.00276-14.

Kumar, S., G. Stecher and K. Tamura (2016). "MEGA7: Molecular Evolutionary Genetics Analysis Version 7.0 for Bigger Datasets." Mol Biol Evol 33(7): 1870-1874 DOI: 10.1093/molbev/msw054. Kumar, Y., P. Aiemsum-Ang, A. C. Ward and M. Goodfellow (2007). "Diversity and geographical distribution of members of the Streptomyces violaceusniger 16S rRNA gene clade detected by cladespecific PCR primers." FEMS Microbiol Ecol 62(1): 54-63 DOI: 10.1111/j.1574-6941.2007.00374.x. Labeda, D. P., C. A. Dunlap, X. Rong, Y. Huang, J. R. Doroghazi, K. S. Ju and W. W. Metcalf (2017). "Phylogenetic relationships in the family Streptomycetaceae using multi-locus sequence analysis." Antonie Van Leeuwenhoek 110(4): 563-583 DOI: 10.1007/s10482-016-0824-0.

Labeda, D. P., M. Goodfellow, R. Brown, A. C. Ward, B. Lanoot, M. Vanncanneyt, J. Swings, S. B. Kim, Z. Liu, J. Chun, T. Tamura, A. Oguchi, T. Kikuchi, H. Kikuchi, T. Nishii, K. Tsuji, Y. Yamaguchi, A. Tase, M. Takahashi, T. Sakane, K. I. Suzuki and K. Hatano (2012). "Phylogenetic study of the species within the family Streptomycetaceae." Antonie Van Leeuwenhoek 101: 32 DOI: 10.1007/s10482-0119656-0).

Lee, L. H., N. Zainal, A. S. Azman, S. K. Eng, B. H. Goh, W. F. Yin, N. S. Ab Mutalib and K. G. Chan (2014). "Diversity and antimicrobial activities of actinobacteria isolated from tropical mangrove sediments in Malaysia." ScientificWorldJournal 2014: 698178 DOI: 10.1155/2014/698178. Liu, L., N. Salam, J. Y. Jiao, H. C. Jiang, E. M. Zhou, Y. R. Yin, H. Ming and W. J. Li (2016). "Diversity of Culturable Thermophilic Actinobacteria in Hot Springs in Tengchong, China and Studies of their Biosynthetic Gene Profiles." Microb Ecol 72(1): 150-162 DOI: 10.1007/s00248-016-0756-2.

Lopez-Lozano, N. E., K. B. Heidelberg, W. C. Nelson, F. Garcia-Oliva, L. E. Eguiarte and V. Souza (2013). "Microbial secondary succession in soil microcosms of a desert oasis in the Cuatro Cienegas Basin, Mexico." PeerJ 1: e47 DOI: 10.7717/peerj.47.

Mahmoud, H. M. and A. A. Kalendar (2016). "Coral-Associated Actinobacteria: Diversity, Abundance, and Biotechnological Potentials." Front Microbiol 7: 204 DOI: 10.3389/fmicb.2016.00204.

Maldonado, L. A., D. Fragoso-Yanez, A. Perez-Garcia, J. Rosellon-Druker and E. T. Quintana (2009). "Actinobacterial diversity from marine sediments collected in Mexico." Antonie Van Leeuwenhoek 95(2): 111-120 DOI: 10.1007/s10482-008-9294-3. 
630

631

632

633

634

635

636

637

638

639

640

641

642

643

644

645

646

647

648

649

650

651

652

653

654

655

656

657

658

659

660

661

662

663

664

665

666

667

668

669

670

671

672

673

674

675

676

677

678

679

Marri, P. R., W. Hao and G. B. Golding (2006). "Gene gain and gene loss in streptococcus: is it driven by habitat?" Mol Biol Evol 23(12): 2379-2391 DOI: 10.1093/molbev/msl115.

Milne, I., D. Lindner, M. Bayer, D. Husmeier, G. McGuire, D. F. Marshall and F. Wright (2009).

"TOPALi v2: a rich graphical interface for evolutionary analyses of multiple alignments on HPC clusters and multi-core desktops." Bioinformatics 25(1): 126-127 DOI: 10.1093/bioinformatics/btn575.

Minckley, W. L. and G. A. Cole (1968). "Preliminary Limnologic Information on Waters of the Cuatro Cienegas Basin, Coahuila, Mexico." The Southwestern Naturalist 13(4): 421-431 DOI: 10.2307/3668909. Mohammadipanah, F. and J. Wink (2015). "Actinobacteria from Arid and Desert Habitats: Diversity and Biological Activity." Front Microbiol 6: 1541 DOI: 10.3389/fmicb.2015.01541.

Okoro, C. K., R. Brown, A. L. Jones, B. A. Andrews, J. A. Asenjo, M. Goodfellow and A. T. Bull (2009). "Diversity of culturable actinomycetes in hyper-arid soils of the Atacama Desert, Chile." Antonie Van Leeuwenhoek 95(2): 121-133 DOI: 10.1007/s10482-008-9295-2.

Pace, N. R. (2009). "Mapping the tree of life: progress and prospects." Microbiol Mol Biol Rev 73(4): 565-576 DOI: 10.1128/MMBR.00033-09.

Pajares, S., L. E. Eguiarte, G. Bonilla-Rosso and V. Souza (2013). "Drastic changes in aquatic bacterial populations from the Cuatro Cienegas Basin (Mexico) in response to long-term environmental stress." Antonie Van Leeuwenhoek 104(6): 1159-1175 DOI: 10.1007/s10482-013-0038-7.

Pajares, S., V. Souza and L. E. Eguiarte (2015). "Multivariate and phylogenetic analyses assessing the response of bacterial mat communities from an ancient oligotrophic aquatic ecosystem to different scenarios of long-term environmental disturbance." PLoS One 10(3): e0119741 DOI: 10.1371/journal.pone.0119741.

Parte, A., W. Whitman, M. Goodfellow, P. Kämpfer, H. J. Busse, M. Trujillo, W. Ludwig and K. Suzuki (2012). Bergey's Manual of Systematic Bacteriology: Volume 5: The Actinobacteria, Springer New York. Prieto-Davo, A., L. J. Villarreal-Gomez, S. Forschner-Dancause, A. T. Bull, J. E. Stach, D. C. Smith, D. C. Rowley and P. R. Jensen (2013). "Targeted search for actinomycetes from nearshore and deep-sea marine sediments." FEMS Microbiol Ecol 84(3): 510-518 DOI: 10.1111/1574-6941.12082.

Qin, S., W. J. Li, S. G. Dastager and W. N. Hozzein (2016). "Editorial: Actinobacteria in Special and Extreme Habitats: Diversity, Function Roles, and Environmental Adaptations." Front Microbiol 7: 1415 DOI: $10.3389 /$ fmicb.2016.01415.

Rajendhran, J. and P. Gunasekaran (2011). "Microbial phylogeny and diversity: small subunit ribosomal RNA sequence analysis and beyond." Microbiol Res 166(2): 99-110 DOI: 10.1016/j.micres.2010.02.003. Rateb, M. E., W. E. Houssen, W. T. Harrison, H. Deng, C. K. Okoro, J. A. Asenjo, B. A. Andrews, A. T. Bull, M. Goodfellow, R. Ebel and M. Jaspars (2011). "Diverse metabolic profiles of a Streptomyces strain isolated from a hyper-arid environment." J Nat Prod 74(9): 1965-1971 DOI: 10.1021/np200470u. Rebollar, E. A., M. Avitia, L. E. Eguiarte, A. Gonzalez-Gonzalez, L. Mora, G. Bonilla-Rosso and V. Souza (2012). "Water-sediment niche differentiation in ancient marine lineages of Exiguobacterium endemic to the Cuatro Cienegas Basin." Environ Microbiol 14(9): 2323-2333 DOI: 10.1111/j.14622920.2012.02784.x.

Ronquist, F., M. Teslenko, P. van der Mark, D. L. Ayres, A. Darling, S. Hohna, B. Larget, L. Liu, M. A. Suchard and J. P. Huelsenbeck (2012). "MrBayes 3.2: efficient Bayesian phylogenetic inference and model choice across a large model space." Syst Biol 61(3): 539-542 DOI: 10.1093/sysbio/sys029. Seth, E. C. and M. E. Taga (2014). "Nutrient cross-feeding in the microbial world." Front Microbiol 5: 350 DOI: $10.3389 /$ fmicb.2014.00350.

Smanski, M. J., D. C. Schlatter and L. L. Kinkel (2016). "Leveraging ecological theory to guide natural product discovery." J Ind Microbiol Biotechnol 43(2-3): 115-128 DOI: 10.1007/s10295-015-1683-9. Souza, V., L. E. Eguiarte, M. Travisano, J. J. Elser, C. Rooks and J. L. Siefert (2012). "Travel, sex, and food: what's speciation got to do with it?" Astrobiology 12(7): 634-640 DOI: 10.1089/ast.2011.0768. Souza, V., J. L. Siefert, A. E. Escalante, J. J. Elser and L. E. Eguiarte (2012). "The Cuatro Cienegas Basin in Coahuila, Mexico: an astrobiological Precambrian Park." Astrobiology 12(7): 641-647 DOI: 10.1089/ast.2011.0675. 
680

681

682

683

684

685

686

687

688

689

690

691

692

693

694

695

696

697

698

699

700

701

702

703

704

705

706

707

708

709

710

711

712

713

714

715

716

717

718

719

720

721

722

723

724

725

726

727

728

729

730

Stach, J. E., L. A. Maldonado, A. C. Ward, M. Goodfellow and A. T. Bull (2003). "New primers for the class Actinobacteria: application to marine and terrestrial environments." Environ Microbiol 5(10): 828841.

Subramani, R. and W. Aalbersberg (2013). "Culturable rare Actinomycetes: diversity, isolation and marine natural product discovery." Appl Microbiol Biotechnol 97(21): 9291-9321 DOI: 10.1007/s00253013-5229-7.

Tamura, K. (1992). "Estimation of the number of nucleotide substitutions when there are strong transition-transversion and G+C-content biases." Mol Biol Evol 9(4): 678-687.

Tanaka, Y., S. Hanada, A. Manome, T. Tsuchida, R. Kurane, K. Nakamura and Y. Kamagata (2004).

"Catellibacterium nectariphilum gen. nov., sp. nov., which requires a diffusible compound from a strain related to the genus Sphingomonas for vigorous growth." Int J Syst Evol Microbiol 54(Pt 3): 955-959 DOI: $10.1099 /$ ijs.0.02750-0.

Tang, J., X. Liu, J. Peng, Y. Tang and Y. Zhang (2015). "Genome sequence and genome mining of a marine-derived antifungal bacterium Streptomyces sp. M10." Appl Microbiol Biotechnol 99(6): 27632772 DOI: $10.1007 / \mathrm{s} 00253-015-6453-0$.

Tian, X., Z. Zhang, T. Yang, M. Chen, J. Li, F. Chen, J. Yang, W. Li, B. Zhang, Z. Zhang, J. Wu, C. Zhang, L. Long and J. Xiao (2016). "Comparative Genomics Analysis of Streptomyces Species Reveals Their Adaptation to the Marine Environment and Their Diversity at the Genomic Level." Front Microbiol 7: 998 DOI: 10.3389/fmicb.2016.00998.

Tiwari, K. and R. K. Gupta (2012). "Rare actinomycetes: a potential storehouse for novel antibiotics." Crit Rev Biotechnol 32(2): 108-132 DOI: 10.3109/07388551.2011.562482.

Tiwari, K. and R. K. Gupta (2013). "Diversity and isolation of rare actinomycetes: an overview." Crit Rev Microbiol 39(3): 256-294 DOI: 10.3109/1040841X.2012.709819.

Trujillo, M. E., R. Riesco, P. Benito and L. Carro (2015). "Endophytic Actinobacteria and the Interaction of Micromonospora and Nitrogen Fixing Plants." Front Microbiol 6: 1341 DOI:

10.3389/fmicb.2015.01341.

Undabarrena, A., F. Beltrametti, F. P. Claverias, M. Gonzalez, E. R. Moore, M. Seeger and B. Camara (2016). "Exploring the Diversity and Antimicrobial Potential of Marine Actinobacteria from the Comau Fjord in Northern Patagonia, Chile." Front Microbiol 7: 1135 DOI: 10.3389/fmicb.2016.01135.

Valdivia-Anistro, J. A., L. E. Eguiarte-Fruns, G. Delgado-Sapien, P. Marquez-Zacarias, J. Gasca-Pineda, J. Learned, J. J. Elser, G. Olmedo-Alvarez and V. Souza (2015). "Variability of rRNA Operon Copy Number and Growth Rate Dynamics of Bacillus Isolated from an Extremely Oligotrophic Aquatic Ecosystem." Front Microbiol 6: 1486 DOI: 10.3389/fmicb.2015.01486.

Ward, A. C. and N. Bora (2006). "Diversity and biogeography of marine actinobacteria." Curr Opin Microbiol 9(3): 279-286 DOI: 10.1016/j.mib.2006.04.004.

Winsborough, B. M., E. Theriot and D. B. Czarnecki (2009). "Diatoms on a continental "island": Lazarus species, marine disjuncts and other endemic diatoms of the Cuatro Cienegas basin, Coahuila, Mexico." Nova Hedwigia, Suppl 135: 257-274.

Wolaver, B. D., L. J. Crossey, K. E. Karlstrom, J. L. Banner, M. B. Cardenas, C. G. Ojeda and J. M. Sharp (2012). "Identifying origins of and pathways for spring waters in a semiarid basin using $\mathrm{He}, \mathrm{Sr}$, and C isotopes: Cuatrocienegas Basin, Mexico." Geosphere 9(1): 113-125 DOI: 10.1130/ges00849.1. Yang, J., X. Li, L. Huang and H. Jiang (2015). "Actinobacterial Diversity in the Sediments of Five Cold Springs on the Qinghai-Tibet Plateau." Front Microbiol 6: 1345 DOI: 10.3389/fmicb.2015.01345. Yoon, J.-H., S. T. Lee, S.-B. Kim, M. Goodfellow and Y. Park (1997). "Inter- and Intraspecific Genetic Analysis of the Genus Saccharomonospora with 16S to 23S Ribosomal DNA (rDNA) and 23S to 5S rDNA Internally Transcribed Spacer Sequences." International Journal of Systematic Bacteriology 47(3): 9.

Zhao, J., L. Guo, Z. Li, C. Piao, Y. Li, J. Li, C. Liu, X. Wang and W. Xiang (2016). "Streptosporangium jiaoheense sp. nov. and Streptosporangium taraxaci sp. nov., actinobacteria isolated from soil and dandelion root (Taraxacum mongolicum Hand.-Mazz.)." Int J Syst Evol Microbiol 66(6): 2370-2376 DOI: 10.1099/ijsem.0.001040. 
731 Zotchev, S. B. (2012). "Marine actinomycetes as an emerging resource for the drug development

732 pipelines." J Biotechnol 158(4): 168-175 DOI: 10.1016/j.jbiotec.2011.06.002.

733

734 